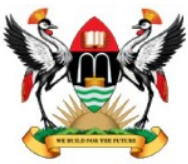

East African School of Higher Education Studies \& Development
Makerere Journal of Higher Education

ISSN: 1816-6822; 9 (1) (2017) 75 - 86

DOI: http://dx.doi.org/10.4314/majohe.v9i1.6

(C) The Author(s) 2017

Reprints \& permission: EASHESD

http://ajol.info/majohe

\title{
Challenges Faced by Visually Impaired Students at Makerere and Kyambogo Universities
}

\author{
Wandera Roberts Otyola ${ }^{1, *}$, Grace Milly Kibanja ${ }^{1}$, Anthony M. Mugagga ${ }^{1}$ \\ ${ }^{1}$ Makerere University [*Corresponding author: wandera@cees.mak.ac.ug]
}

\begin{abstract}
This study aimed at investigating the challenges faced by visually impaired students in Makerere and Kyambogo Universities. The study followed a cross-sectional survey design and involved 200 respondents (50 visually impaired students, 50 lecturers, 50 university administrators and 50 students who were not visually impaired). Data was collected using questionnaires, interviews and document review. The findings revealed that the visually impaired students receive bursaries and allowances from government and non-government organizations; meals, accommodation and scholastic materials from their universities; extra time during examinations; oral examinations; and buddy support. However, constraining limitations in the methods of instruction and assessment used and the instructional materials provided were noted. On the basis of these findings, recommendations towards the better education of the visually impaired students are made.
\end{abstract}

Keywords: Visual impairment; Inclusive education; Special needs education.

\section{$1 \quad$ Introduction}

There is an increasing number of visually impaired students in public Universities in Uganda. These students attend mainstream lectures (inclusive education) and are examined on the same subject content with their peers. Inclusion of blind and low vision children in mainstream education is beneficial not only to the blind/low vision child but to all other students in schools because it enhances social integration (Anne, 2004). It helps change the negative attitude and misconceptions people have of the blind and low vision and it is an opportunity to prepare them for their future roles in society. Blind and low vision children interact with other children in regular school settingsplaying and sharing things and ideas. It helps them to appreciate each other's strengths and limitations. They learn the norms and values of the community in 
which they are and this prepares them for the world outside of school. Students who have been with them in schools will know their potential and will give them chance to participate in social functions and other programmes.

Furthermore, inclusion will promote healthy competition amongst students who are blind or low vision and regular students. When blind/ low vision children perform well in class, this will motivate the regular students to strive to work harder for they will think that if the blind/ low vision child can do well they can do the same. The Ministry of Education and Sports considers issues of special needs education to be cross-cutting (Musasizi, 2009), so it is the development funding attached to the different departments which is expected to cater for children with special needs. There is no special curriculum designed for children with special needs.

At Kyambogo University, the Faculty of Special Needs Education has a ramp and can be accessed by persons using crutches or wheelchairs. However, most buildings, including the Senate Building, are inaccessible for people with disabilities. Every year, government provides sponsorship at university level to 4,000 students under the merit government sponsorship scheme, of which 64 are students with special needs who include sportsmen/women, physically handicapped and visually impaired. These special students are distributed through all the public universities which include Makerere, Kyambogo, Mbarara, Gulu and Busitema Universities. However, the visually impaired students are mainly admitted to Makerere and Kyambogo Universities.

These students face a lot of challenges. Apart from this consideration given to these few; many visually impaired students are admitted on private scheme in these two public universities. These seem to face more challenges in their studies that affect their academic achievement.

Many studies have discussed the difficulties that face the handicapped in the educational environment. Hodges and Keller (1999) made a study aimed at recognizing the extent to which students perceive the process of inclusion of handicapped students in the university. The results indicated that there were many problems that faced the visually impaired students, especially in the area of transport and developing social relationships with their peers.

Hougann (1999) conducted a study aimed at identifying the challenges faced by visually handicapped students in higher education institutions. The results indicated many problems. For example the absence of counselling services, few Braille printed books, lack of visual readers, the difficulty of adjustment with university life, teachers' neglect of their special needs, and the problem of taking exams and transport in were the most important.

Fuller et al. (2004) also studied obstacles that faced the handicapped at university. The results of the study indicated there were many obstacles such as the fast rate of the teachers' speech during the lectures, as well as difficulty in participating in the discussion and answering the questions. Also some lectures 
resented allowing disabled students to tape the lectures, and it was hard to access the educational centres. There was a lack of suitable computer programs.

Masaedeh's (1995) study aimed at identifying the problems of handicapped students in Jordanian universities. The results indicated that the most obvious problems were those which were related to the services. In addition, there were many concerns about the future of disabled students, and their psychological, social and health issues. On the other hand, the study did not show any significant differences due to the gender of the disabled grade level type of disability.

Ibrahim (2001) studied the problems of visually handicapped students in the University of Jordan. The results of the study revealed the existence of problems such as using the library, transport, difficulties in teachers' understanding about their needs. The study did not show any significant differences due to the handicapped gender, the degree of disability, level of education. He further asserts that it is because of several reasons which included lack of interaction between special needs and regular students, teachers do not have sufficient skills in teaching techniques required to handle the inclusive programme. Therefore, in order for inclusive programme to take place successfully, it requires a regular classroom that is sensitive and attended to the students' needs and abilities.

From his findings, he identifies the following problems; Itinerant and classroom teachers feel lack of training about inclusive education and still need that training. Itinerant teachers have difficulty in some lessons; some normal students treat the visually impaired badly. Facilities in regular schools such as classrooms, educational tools, are still not appropriate. Some teachers do not support inclusive education and some parents are not communicative. Introduction of itinerant teachers to classroom teachers are not facilitated well. Age factor is a problem for itinerant teachers in learning or studying new things (Bob, 2002).

Bob (2002) states that, the visually handicapped born blind may have restricted concept development because of lack of vision. This is because vision plays an important role in environmental input. What children see, they assimilate and integrate in the brain. Another way of visual impairments typically slow development is by making it harder for children to learn from experience without their parents or teachers doing anything out of the ordinal, to teach them. This is called accidental learning.

Apart from early identification, inadequate trained teachers are also a factor that militates against effective inclusion. Teachers need to be equipped with skills in screening, identification and management of children who are blind and low vision. The above challenges cannot be addressed if the resources allocated to inclusion are too limited. Presently Government has procured a bus and a Braille printing press for children who are blind and have low vision. 
However, inclusion will be only a slogan if there are inadequate resources for inclusion programmes. Inclusion is not a matter of placing children who are blind and low vision in regular schools but providing adequate resources in the form of funds for itinerant teaching service, teaching/learning materials, making schools more accessible and inclusive. Aside from allocation of resources, societal negative attitude however can also contribute to the exclusion of children who are blind and have low vision. Most people tend to see blind and low vision as liabilities and do not treat them with respect or give them their right due in society.

The UNESCO Bulletin on special education (1994) observed that the blind and partially sighted children have greater problems in learning, communicating and interacting in an ordinary school than their sighted classmates. This is because children do not receive adequate educational and developmental help during their pre-school years, neither their parents nor regular classroom teachers are equipped to give them special assistance they require in the school situation. Therefore in this study we answer the following questions;

1. What are the challenges faced by visually impaired students in Makerere and Kyambogo Universities?

2. What remedies have been put in place to solve the challenges faced by visually impaired students at Makerere and Kyambogo Universities?

\section{$2 \quad$ Methodology}

The research adopted the cross sectional survey design. We employed selfadministered questionnaires, which were administered to lecturers, university administrators and non-visually impaired students. The visually impaired students were interviewed. The sample was 200 , comprised of 50 visually impaired students, 50 lecturers, 50 University administrators and 50 nonvisually impaired students. The visually impaired students were identified using the snowball method while the lecturers, university administrators and nonvisually impaired students were identified using random sampling.

\section{$3 \quad$ Results}

The challenges identified by the respondents are summarised in Tables 1, 2, 3 and 4. 
Table 1: Challenges cited by Visually Impaired Students

\begin{tabular}{lll}
\hline Challenges & Frequency & Percentage \\
\hline Long distance from home to University & 2 & 4 \\
Late coming & 2 & 4 \\
Lack of tuition & 3 & 6 \\
Lack of writing materials & 2 & 4 \\
Lack of special needs lecturer & 1 & 2 \\
Hand outs are given in print form & 2 & 4 \\
Socialization & 2 & 4 \\
Inaccessibility to lecture rooms & 2 & 4 \\
Writing problems & 2 & 4 \\
Usually at typing notes & 2 & 4 \\
Poor movement & 2 & 4 \\
Text books & 3 & 6 \\
Isolated & 3 & 6 \\
Movement that is pot holes around the university & 3 & 6 \\
Non cooperative staff & 3 & 6 \\
Competition with other students & 2 & 4 \\
Deprived attention/no attention & 2 & 4 \\
Dictation & 1 & 2 \\
Lack of equipment & 3 & 6 \\
Negative attitude & 2 & 4 \\
Reading problems & 3 & 6 \\
Usually under looked & 3 & 6 \\
Total & 50 & 100 \\
\hline
\end{tabular}

Table 1 shows that visually impaired students are faced by a lot challenges in achieving their academic goals: $6 \%$ are faced with reading problems, lack of equipment, isolation, lack of text books, movement problems and tuition fees. Some of these students face challenges like materials, movement and mobility problems, negative attitudes, academic competition with other students, and deprived attention in the lecture rooms due to noise from non-disabled students.

Table 2: Challenges cited by Lecturers

\begin{tabular}{lll}
\hline Challenges & Frequency & Percent \\
\hline Lack of knowledge of Braille & 13 & 26.0 \\
Noise from Braille machines & 10 & 20.0 \\
Quite Slow & 8 & 16.0 \\
Over reliance on buddies & 7 & 14.0 \\
Illustration on chalk board & 3 & 6.0 \\
Few writing materials & 5 & 10.0 \\
Failure to interpret Braille language & & 100 \\
Total & 50 & \\
\hline
\end{tabular}


Table 2 shows that several challenges are faced by visually impaired students according to lecturers $26 \%$ lack knowledge of Braille, $20 \%$ of noise made by Braille, $16 \%$ are quite slow, $14 \%$ rely on buddies, $10 \%$ have few writing materials, $8 \%$ fail to interpret and Braille language and $6 \%$ fail to see or observe illustrations on chalkboard. Most lecturers who handle visually impaired are less trained in teaching and handling of these students. The methods of teaching that they use such as lecture methods and dictation of notes to students do not favour the proper teaching and learning of the students. These teachers do not understand Braille instruction which is used by visually impaired students. So they end up examining and assessing them using inappropriate methods that make the study not to perform well. The way these students write their responses is also a challenge in that some of them use Braille which is not transcribed into normal English language. So some lectures have to look for transcribers of Braille which sometimes is very difficult. What if the transcriber is not efficient is also another problem which may make these students to actually acquire well academically.

Table 3: Challenges by University Administrators

\begin{tabular}{lll}
\hline Challenges faced & Frequency & Percent \\
\hline Problems with registration & 11 & 22.0 \\
Lack of staff trained in Braille & 13 & 26.0 \\
Receiving help from guides during exams & 08 & 16.0 \\
Too slow when writing exams & 04 & 8.0 \\
Isolation & 10 & 20.0 \\
Lack of staff to handle blind & 04 & 8.0 \\
Total & 50 & 100 \\
\hline
\end{tabular}

According to the University administrators, there are a number of challenges faced by visually students at University $26 \%$ lack staff which is trained in Braille, $22 \%$ of the visually impaired students find problems while registering, $20 \%$ of these students are usually isolated, $16 \%$ receive help from their helpers or guides, while $8 \%$ lack administrative staff to handle issues of disability and are also too slow while writing exams. Lack of training of university administrators in issues of disability on challenges faced by the visually impaired students. Most of them do not understand the Brailing language used by the blind. They also find problems with registering or feeding their marks into the university systems. 
Table 4: Challenges cited by Non-Visually impaired students

\begin{tabular}{lll}
\hline Challenge & Frequency & Percent \\
\hline Lack of Brailed text books & 11 & 22.0 \\
Mobility problem & 13 & 26.0 \\
Lack of hand outs & 7 & 14.0 \\
Dictation- they are slow & 5 & 10.0 \\
Difficulty in writing course works & 4 & 8.0 \\
Poor spellings & 2 & 4.0 \\
Lack of machines like laptops, computers and Braille machines & 3 & 6.0 \\
Examination time is not enough & 3 & 6.0 \\
Lack of accommodation & 2 & 4.0 \\
Total & 50 & 100 \\
\hline
\end{tabular}

Table 4 shows that non-visually impaired students find that $26 \%$ of the visually impaired students have challenges with their movement, $22 \%$ lack of brailed text books, $14 \%$ of all hand outs are given in typed print which does not favour the blind students, $10 \%$ are show while brailing dictated notes by the lecturers, $8 \%$ find difficulty in writing course work, $6 \%$ lack machine such as laptops, Braille, computers and also examination time or duration is inadequate for proper completion, $4 \%$ of the visually impaired students lack accommodation and have poor spellings while writing examinations, course works or notes.

In summary the visually impaired students face the following challenges; general lack of training in the use of Braille instruction, lack of Braille machines and their materials, slow in writing during lectures and during exams and problems in their mobility around the university.

\subsection{Proposed Remedies}

The government through acts of parliament can enact laws and policies such as disability acts to emphasize the provision of education to disabled children from early childhood development, primary, secondary and tertiary institutions.

There should be proper representation in parliament and councils by persons with disabilities so that at parliament and local councils there should be a representative for each form of disability including the blind people so that they can legislate and formulate laws to aid in the teaching and education of the visually handicapped.

Creation of a sister ministry handling people with disabilities is a necessity so that issues of visually impaired can be handled separately. Also in this ministry there should be a condition that the specialists in issues of disability should be the first priority to be employed. This is due to the understanding of policies and being knowledgeable on matters of disability. 
There should be influence in enacting disability friendly legislation in acts of parliament e.g. Local Council Act 1997; UNISE Act, Traffic and Road Safety Act. It is expected that these should gradually have a positive impact on the quality of life and education of people with disabilities, visually handicapped inclusive.

There should be establishment of more special schools at primary, secondary and at university level where inclusive education can be designed in such a ways that curricular are designed for particular forms of disability.

There should be adequate training for special teachers and in service training for current teachers in the mainstream schools to cater for the educational development of persons with disability.

There should be structural and other adaptations of all educational institutions to the needs of persons with disabilities and promotion of specialized institutions that facilitate research and development of their education.

An operational policy framework is one of the strategies in which the challenges of inclusion can be addressed. A framework will specifically outline the issues and the resources needed for effective inclusion. The framework on special needs education (supported by save the children Sweden) which is presently being developed will go a long way to address the outlined issues.

Assessment centres are ideal for early clinical identification, diagnosis, appropriate intervention and placement for the blind and low vision children. This centre should have medical and educational personnel. Medical personnel will assess students for refractive error and functional vision assessment. The students will then be referred to the educational team for appropriate intervention and placement.

Trained teachers are a powerful resource in the achievement of quality and relevant education. To handle children who are blind and low vision, teachers must be specifically and adequately trained to handle such children. The training programme on special needs education in the Ugandan universities should be made more detailed. Such trained teachers however must be remunerated to motivate them to put more effort in their work.

It is obvious that the above outlined strategies cannot be achieved without adequate allocation of resources. There is however, the need to make schools more inclusive with the availability of accessible schools, support services teaching and learning materials. The education department should endeavour to allocate a portion of its budget to inclusive education. Donors and nongovernmental organizations can also contribute by providing appropriate resources for facilitating successful inclusion.

However, if all the resources are in place and all the required interventions done and society's attitude towards the blind and low vision is negative, the resources put in place will be a waste. If communities, trained teachers, 
students and other members of society do not appreciate the blind/low vision, empathize with them and give the opportunities to unearth their potentials, the resources put into inclusion will be wasted. Any programme should also pay attention to community and family awareness and participation to yield positive results.

More sponsorship for the Visually Impaired should be extended to other government aided universities such as Gulu, Busitema, Mbarara and Muni universities. Also private universities should begin admitting theses students though their maintenance and requirements are very costly.

The researcher also recommends that since there are special primary and secondary schools for the visually impaired there should also establish higher institutions of learning for these people at both college and university level.

The government of Uganda should also set up stringent policies and laws to guide the education of the visually impaired at institutions of higher learning especially visually impaired.

There should be proper and adequate training of the staff and administrators who hand these visually impaired students in the institutions they attend.

\section{Discussion, Conclusions and Recommendations}

The challenges are organized in form of those faced by the visually impaired students themselves, the lecturers, university administration and the nonvisually impaired students. These students have a number of challenges around the university environments which they face during lectures, accessibility, movement, daily living skills and socially which eventually affect their academic achievements such as lack of Braille machines, textbooks in Braille form and slates. Socially they are faced by a number of challenges such as being under looked by their fellow students and lecturers as non-achievers and hence getting isolated by these people. Some of the fellow students have negative attitudes towards them making it difficult to render any help or assistance to them. This is supported by many studies especially by Hodges and Keller (1999) who did a study on difficulties faced by the handicapped in the educational environment. He discovered that they were many problems faced by visually impaired students such as lack of transport and developing a social relationship with their peers. Hougann (1987) also looked at a study of identifying problems faced by the visually handicapped in higher education institution. The results indicated different problems in form of absence of counselling services, few or non-Braille printed books, lack of visual readers, difficulty in adjusting to university life and teachers neglecting the special needs of the visually impaired students. 
During lectures they find problems in attention during dictation of notes, reading problems and writing problems since they use Braille machines which make a lot of noise for other students. This could be the reason why they admit very few for particular courses so that their noise during notes taking can be limited. In terms of mobility and orientation around the university they find it difficult in accessing some of the lecture rooms, offices and places of convenience. They move long distances in case they are on private sponsorship and eventually reach late for their lectures which affects their academic achievement greatly. There is also a challenge of not being assessed well or appropriately. Some of these visually impaired students are not taught by specialised needs teachers who know how to handle them. They sit for their exams in Braille form which require interpretation by a knowledgeable person in Braille communication or language. This purely happens in some departments in Kyambogo University but for Makerere University most of the lecturers who teach these students are not trained in Braille and there are no special needs teachers.

Most lecturers who teach or attend to visually impaired students are faced by a number of challenges mostly in communicating. Most of them are not trained as special needs teachers, not trained in Braille language and even interpreting Braille instruction. During teaching lesson, the visually impaired students are quite slow while writing / taking notes and their Braille machines also make a lot of noise for both the students and interrupt with the lecturers' dictations. These students most times cannot see or observe illustrations and examples written on the chalkboards. With all these challenges these kind of students are affected academic and that is the reason most of them perform moderate or below average. This is in line with the study done by Fuller et al. (2004) who studied the obstacles faced handicapped at Universities. The results indicated that there were many obstacles such as fast rate of teachers' speech during the lectures as well as difficulty in participating in discussions and answering the questions. Also some lecturers resented allowing disabled students to tape the lectures and it was hard to access the educational centres.

Challenges faced by impaired students in the views of university administrators include difficulty during registration which at times is on internet or online which they cannot access. They find them socially isolated and there is lack of trained staff in special needs to handle these students. They find them too slow while writing their exams and lack of staff to interpret the written answers in Braille language. This is supported by the study by Fuller et al (2004) which states that there is lack of suitable computer programmes in universities which can be used by visually impaired students.

Non-visually impaired students stated that lack of Braille text books to be read by visually impaired students is the main challenge faced by these students. Then there is mobility problem around the campus. 
They also have problems during dictation of notes in lectures and poor spelling written by them since they cannot see what correct spellings are written on the chalkboard by the lecturer. There is inadequate supply of writing and reading equipment such as Braille machines, laptops and computers. Time given to the visually impaired students is not adequate or enough for these students to complete their written exams. There is the negative aspect of inclusive education to the non-visually impaired students. This is reflected during lecture time when their Braille machines make a lot of noise and disrupt the proper learning of their peers. This is supported by Fletcher (2010) who stated that while there is evidence of positive effects of inclusion of students with disabilities opponents of this idea maintain that there is less evidence of the overall benefits of inclusion of the classmates of the students with disabilities.

Secondly visually impaired students face a number of challenges in the course of pursuing their academic goals. They get challenges in mobility around the university like poor accessibility to the lecture rooms, late coming and over reliance on guides. When it comes to the learning process, they face a number of challenges such as writing and reading problems, lack of Braille knowledge, slow in dictation, failure to see illustrations on chalkboard, inadequate time given for sitting examinations, etc.

In terms of socialization these students face challenges of isolation, negative attitude, non-cooperative staff/students, and poorly trained tutors / or lecturers in Special Needs Education. In terms of provision to aid their learning processes, they lack scholastic materials and general equipment and materials for their proper learning.

\section{References}

Anne, N. M. (2004). The Gambia: Department of state for Basic and Secondary Education, Special Needs Education.

Bob, G. (2002). Learning Disabilities ( $4^{\text {th }}$ edition). London: Oxford University Press.

Fletcher, J. (2010). Spill over effects of classmates with emotional problems on test scores in early elementary school. Journal of Policy Analysis and Management, 29 (1), 69-83.

Fuller, M., Healy, A. Bradley, \& Hall, Y. (2004). "Barriers to learning, a systematic Study of the experience of disabled students in one university". Studies in higher Education, 29 (3), 303-318. 
Hogde, J. \& Keller, J. (1999).”Visually Impaired Students' Perception of their Social Integration in College". Journal of Visual Impairment and Blindness. $3(2), 149-162$.

Hougann, E, (1987). Visually impaired students in higher Education in Norway. Journal of Visual Impairments and Blindness. 4 (92), 235 -250.

Ibrahim, M. (2001). The problems of Visually Impaired Students in Jordanian University. Unpublished thesis Jordan University, Amman; Jordan.

Keller, G., Warrack. B. \& Bartel, H. (1999). Statistics. California: Duxbury Press.

Masaedeh, A, (1995). The problems of handicapped Students in Jordanian University. (Unpublished thesis). Yarmouk University, Irbed, Jordan

Musazizi, S. (2009, December). The New Vision. Kampala -Uganda

UNESCO (1994). The Salamanca Statement and framework for action on Special Needs Education adopted by the World. 